\title{
Aberrant methylation of cell-free circulating DNA in plasma predicts poor outcome in diffuse large B cell lymphoma
}

\author{
Lasse Sommer Kristensen ${ }^{1 *}$, Jakob Werner Hansen ${ }^{1}$, Søren Sommer Kristensen', Dorte Tholstrup',
} Laurine Bente Schram Harsløf ${ }^{1}$, Ole Birger Pedersen², Peter De Nully Brown ${ }^{1}$ and Kirsten Grønbæk ${ }^{1}$

\begin{abstract}
Background: The prognostic value of aberrant DNA methylation of cell-free circulating DNA in plasma has not previously been evaluated in diffuse large B cell lymphoma (DLBCL). The aim of this study was to investigate if aberrant promoter DNA methylation can be detected in plasma from DLBCL patients and to evaluate this as a prognostic marker. Furthermore, we wanted to follow possible changes in methylation levels during treatment. Seventy-four patients were enrolled in the study, of which 59 received rituximab and CHOP-like chemotherapy. Plasma samples were collected from all patients at the time of diagnosis and from 14 healthy individuals used as controls. In addition, plasma samples were collected during and after treatment for surviving patients. In total, 158 plasma samples were analyzed for DNA methylation in the promoter regions of DAPK (DAPK1), DBC1, MIR34A, and MIR34B/C using pyrosequencing.
\end{abstract}

Results: Aberrant methylation levels at the time of diagnosis were detected in $19,16,8$, and $10 \%$ of the DLBCL plasma samples for DAPK1,DBC1, MIR34A, and MIR34B/C, respectively. DAPK1 methylation levels were significantly correlated with $D B C 1$ and MIR34B/C methylation levels $(P<0.001)$. For the entire cohort, 5-year overall survival (OS) rates were significantly lower in the groups carrying aberrant DAPK1 $(P=0.004)$ and DBC1 $(P=0.044)$ methylation, respectively. DAPK1 methylation status were significantly correlated with stage $(P=0.015)$, as all patients with aberrant DAPK1 methylation were stages III and IV. Multivariate analysis identified DAPK1 as an independent prognostic factor for OS with a hazard ratio of 8.9 (95 \% Cl 2.7-29.3, $P<0.0007)$. Patients with DAPK1 methylated cell-free circulating DNA at time of diagnosis, who became long-term survivors, lost the aberrant methylation after treatment initiation. Conversely, patients that maintained or regained aberrant DAPK1 methylation died soon thereafter.

Conclusions: Aberrant promoter methylation of cell-free circulating DNA can be detected in plasma from DLBCL patients and hold promise as an easily accessible marker for evaluating response to treatment and for prognostication. In particular, aberrant DAPK1 methylation in plasma was an independent prognostic marker that may also be used to assess treatment response.

Keywords: Diffuse large B cell lymphoma, Plasma, Circulating DNA, Liquid biopsy, DNA methylation, Epigenetics, Prognostic markers, Biomarker

\footnotetext{
* Correspondence: lasse@mbg.au.dk

${ }^{1}$ Department of Haematology, Rigshospitalet, Blegdamsvej 9, Copenhagen,

Denmark

Full list of author information is available at the end of the article
} 


\section{Background}

Diffuse large B cell lymphoma (DLBCL) is the most prevalent subtype of $B$ cell non-Hodgkin lymphoma [1]. The prognosis is relatively good for patients responding to the current standard-of-care treatment: rituximab combined with cyclophosphamide, doxorubicin, vincristine, and prednisolone (R-CHOP). However, about one third of the patients, who do not respond or relapse within 5 years after treatment, have a poor prognosis [2, 3], and for DLBCL patients in first complete remission (CR), there is no survival benefit associated with routine imaging [4].

Thus, there is a need for molecular markers that can rapidly and accurately identify patients who will not respond to the treatment or have an increased risk of relapse, as well as markers to assess treatment response, and to detect minimal residual disease (MRD) [5].

Methylation of cytosine residues within the CpG dinucleotide plays important roles in transcriptional regulation during differentiation of normal human cells, but aberrant methylation patterns are also involved in most human cancers [6], including B cell lymphomas [7]. Recent studies have shown that epigenetic modifiers, such as EZH2, MLL2, and TET2, are frequently mutated in DLBCL and associated with altered epigenetic patterns [8-10]. Interestingly, it has also been shown that relapsing patients have more intra-tumor DNA methylation heterogeneity at diagnosis compared to relapse-free patients [11].

Silencing of tumor suppressor genes in cancer often involves methylation of their promotor regions, and the detection of these methylation events in a large range of different tissues shows great promise as diagnostic, prognostic, and predictive markers in various human cancers [12, 13]. Ideally, DNA methylation markers should be detectable in readily accessible body fluids or tissues.

Solid tumors are known to shed cell-free circulating DNA (cfDNA) into the bloodstream, which can be isolated from plasma or serum. Normal cells, including leukocytes, also shed cfDNA into the bloodstream; however, it has been shown that individuals with solid cancers harbor the same mutations and methylation patterns in cfDNA from plasma as in their tumor cells [14].

Tumor-derived cfDNA in serum and plasma has been detected in patients with DLBCL based on next-generation sequencing (NGS) of tumor-specific recombination of the immunoglobulin genes [15-17]. It has also recently been shown that somatic mutations reflecting the genetic changes of primary tumors can be detected in cfDNA from DLBCL patients at time of diagnosis $[18,19]$. While these studies prove the usefulness of detecting tumor-derived cfDNA in DLBCL, much more work is clearly needed before standardized tests of cfDNA can be applied in routine clinical settings [5].
In this contribution, we focus on the detection of tumor-derived cfDNA in plasma, as serum is likely to contain DNA derived from leukocytes which lyse during serum processing $[20,21]$. Furthermore, we focused on the detection of DNA methylation in the promoter regions of the tumor suppressor genes $D A P K 1, D B C 1$, $M I R 34 A$, and $M I R 34 B / C$, which have been shown to be frequently methylated in DLBCL biopsies [22-25]. In addition, methylation of DAPK1 has been shown to be an independent prognostic factor in DLBCL [22, 26], but none of these markers have been investigated in easily accessible tissues, such as plasma. We hypothesized that aberrant promoter DNA methylation can be detected in plasma from DLBCL patients and have prognostic value. Furthermore, we hypothesized that aberrant promoter DNA methylation in plasma may serve as a marker to assess treatment response.

\section{Methods \\ Patient samples}

This retrospective study examined material from 74 DLBCL patients treated at Rigshospitalet, Denmark, who had been diagnosed with DLBCL based on standard histology and immunophenotyping according to the WHO guidelines. None of the patients were under treatment for another malignancy at time of inclusion. Peripheral blood (PB) plasma was collected from all patients at the time of diagnosis and 14 days after the fourth and last treatment cycle, respectively, and 3 months after end of treatment from surviving patients. In addition, PB plasma samples were collected from 14 healthy blood donors from the Danish Blood Donor Study [27]. The patients were diagnosed from 2003 to 2007 and at least 5 years of clinical follow-up were available for all patients except three.

\section{DNA extraction and sodium bisulfite conversion}

DNA extractions from plasma were performed with the ROCHE MagNa Pure, using the MagNA Pure LC Total Nucleic Acid Isolation kit (Roche Diagnostics, Mannheim, Germany) for all plasma samples from the normal controls, and the patient samples from time of diagnosis and end of treatment. The QIAsymphony Circulating NA Kit (48), cus, G (QIAGEN, Hilden, Germany) was used for the samples collected during treatment. DNA concentrations were measured using the Qubit flourometer (ThermoFisher Scientific, Waltham, MA, USA). Between 10 and 100 ng, DNA were converted with the EZ DNA Methylation kit (Zymo Research, Irvine, CA, USA) according to the manufactures' instructions.

\section{DNA methylation detection using pyrosequencing}

Traditional methylation-independent PCR pyrosequencing assays [28] were designed to target the promoter regions of $D A P K 1, D B C 1, M I R 34 A$, and $M I R 34 B / C$. The PCR and 
sequencing primers were designed using the PyroMark Assay Design 2.0 software (QIAGEN). The primer sequences and information about the assays can be found in (Additional file 1: Table S1). PCR cycling was performed on the Gene PCR System 9700 (Applied Biosystems, Foster City, CA, USA). The cycling protocol started with 1 cycle of $95{ }^{\circ} \mathrm{C}$ for $15 \mathrm{~min}$, followed by 45 cycles of $95^{\circ} \mathrm{C}$ for $20 \mathrm{~s}$, $58{ }^{\circ} \mathrm{C}\left(60{ }^{\circ} \mathrm{C}\right.$ for the DAPK 1 assay) for $20 \mathrm{~s}, 72{ }^{\circ} \mathrm{C}$ for $20 \mathrm{~s}$, and 1 cycle of $72{ }^{\circ} \mathrm{C}$ for $10 \mathrm{~min}$. For the reaction mixtures, the PyroMark PCR Master Mix (QIAGEN) was used at a final concentration at $1 \times$, resulting in a final $\mathrm{MgCl} 2$ concentration of $1.5 \mathrm{mM}$. Final primer concentrations were $200 \mathrm{nM}$ and $1 \mu \mathrm{L}$ bisulfite converted DNA was used as template. Samples were sequenced on the PyroMark Q24 (QIAGEN) using the PyroMark Gold Q24 reagents (QIAGEN), according to the manufactures' instructions. Methylated DNA (Chemicon, Millipore, Billerica, MA), unmethylated DNA (QIAGEN), and a no template control (NTC) were included in all experiments. Aberrant methylation was defined as a methylation level above the mean methylation level plus two standard deviations of the control group. The cutoffs were 5.5, 20.9, 4.2, and $7.8 \%$ for $D A P K 1, D B C 1, M I R 34 A$, and $M I R 34 B / C$, respectively.

\section{Statistical analyses}

Statistical analyses were performed in SPSS 19.0 for Windows (SPSS Inc.) and in Prism 6 (GraphPad software, San Diego, CA, USA). Goodness-of-fit linear regression was used to evaluate possible relations between methylation levels and DNA concentrations as well as DAPK1 methylation levels and methylation levels of the other markers by employing an $\mathrm{F}$ test to evaluate if the slopes were significantly different from zero. Correlations between 5-year overall survival (OS) rates and methylation status as well as clinical characteristics were estimated using the Kaplan-Meier method with the use of a log-rank test. Hazard ratios (HR) and $95 \%$ confidence intervals (CI) were calculated using a univariate Cox proportional hazard model. The clinical characteristics and treatment outcomes were compared according to DAPK1 methylation status using Students $T$ tests, Pearson's chi-square tests, or Fisher's exact tests when expected values were below five. For assessment of independent predictors of OS, a multivariate Cox regression hazard model was applied. Any differences were considered to be statistically significant when the $P$ value was $<0.05$.

\section{Results}

\section{cfDNA concentrations in the plasma samples}

The cfDNA concentrations were significantly higher for the samples collected at time of diagnosis compared to the normal control samples $(P<0.0001)$, while there was no difference between the samples from time of diagnosis and the samples collected after treatment (Fig. 1).

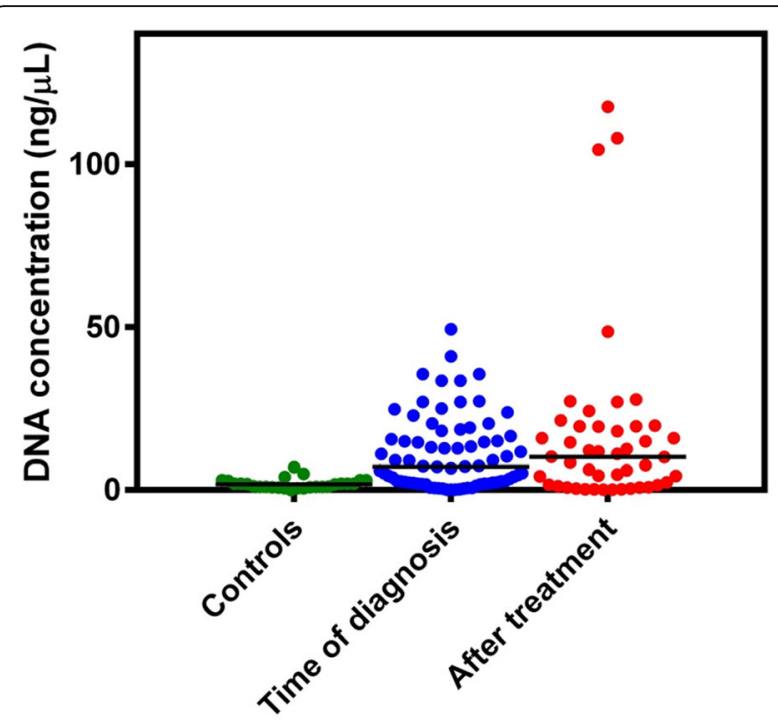

Fig. 1 DNA concentrations in the control plasma samples and the plasma samples taken at time of DLBCL diagnosis and following treatment

Detection of aberrant methylation in the plasma samples The methylation analyses were successful for all samples for all markers except $M I R 34 B / C$, which failed for 12 and 13 of the diagnostics samples and samples collected after end of treatment, respectively. For DAPK1 aberrantly methylated DNA in plasma was detected in 14 $(19 \%)$ of the patients at the time of diagnosis, while only 2 (4 \%) were methylated after end of treatment. For $D B C 1, M I R 34 A$, and $M I R 34 B / C$, aberrantly methylated DNA were detected in $12(16 \%), 6(8 \%)$, and $6(10 \%)$ of the patients at the time of diagnosis, respectively, while 6 (13\%), $4(9 \%)$, and 5 (15\%) were methylated after end of treatment, respectively (Fig. 2). DAPK1 methylation levels were significantly correlated with $D B C 1$ and $M I R 34 B / C(P<0.001$ for both), but not with $M I R 34 A$ methylation levels (Additional file 2: Figure S1). None of the markers were correlated with the DNA concentration in the samples (Additional file 3: Figure S2).

\section{Survival analyses according to methylation status and DNA concentrations}

The prognostic value of methylated cfDNA levels at time of diagnosis was evaluated by analyzing OS rates according to each of the four markers for all patients with clinical data available $(n=71)$ and in separate analyses including only patients receiving rituximab $(n=59)$.

When analyzing all patients, the 5-year OS rates were 35.7 and $70.0 \%$ in the DAPK1 methylated group and unmethylated group, respectively. The hazard ratio for death in the methylated group was 3.08 (95\% CI, 1.37 to $6.93 ; P=0.004)$. The 5 -year OS rates were 41.7 and $67.8 \%$ in the $D B C 1$ methylated and unmethylated 

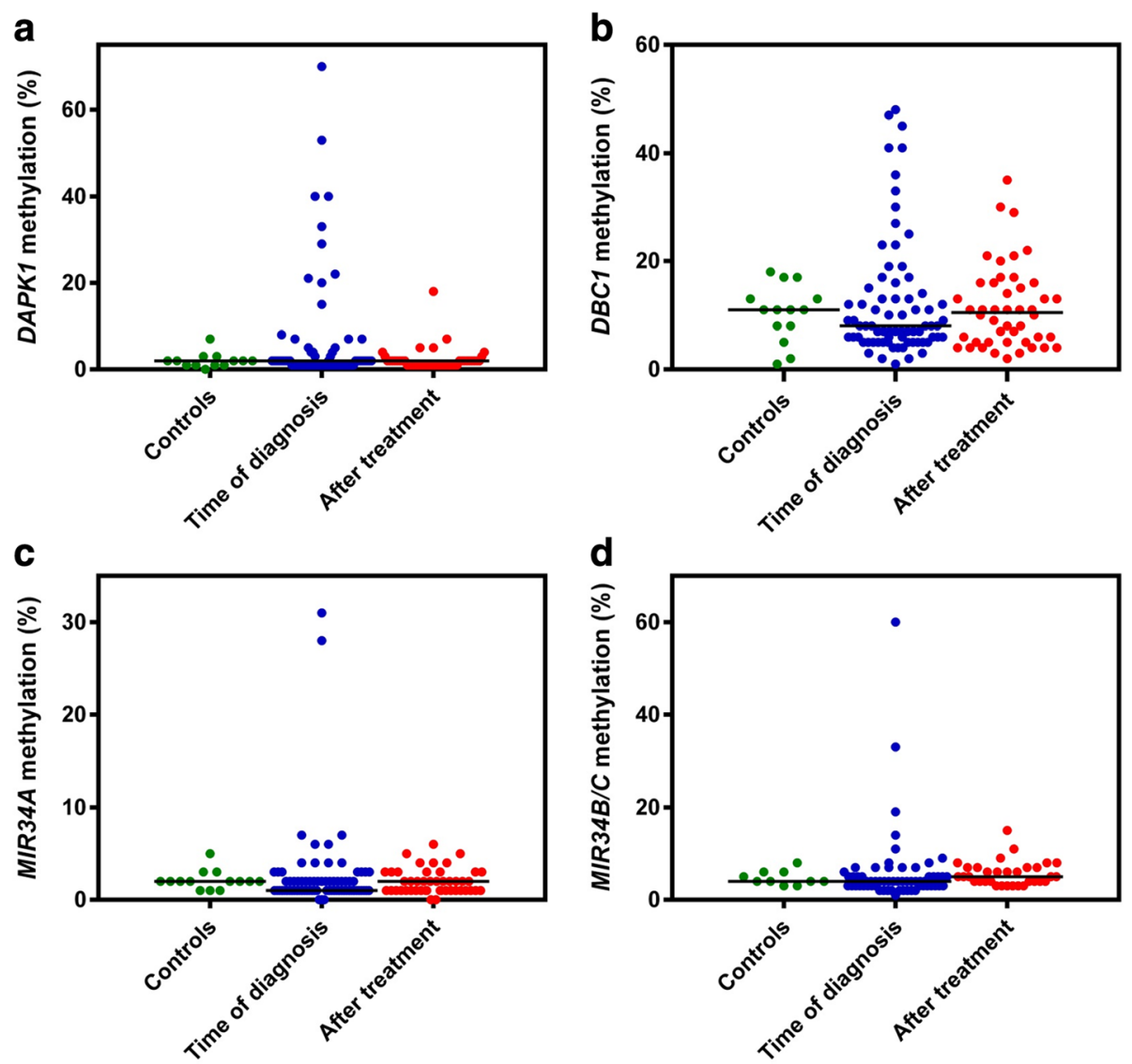

Fig. 2 Methylation levels in the plasma samples. The solid lines represent medians. a DAPK1 methylation levels. b DBC1 methylation levels. c MIR34A methylation levels. d MIR34B/C methylation levels

group, respectively. The hazard ratio for death in the methylated group was 2.38 (95\% CI, 1.00 to 5.66; $P=$ 0.044 ). The 5-year OS rates were 83.3 and $60.9 \%$ in the MIR34A methylated and unmethylated group, respectively. The hazard ratio for death in the methylated group was 0.40 (95\% CI, 0.05 to 2.93; $P=0.348$ ). The 5 -year OS rates were 50.0 and $67.9 \%$ in the $M I R 34 B / C$ methylated and unmethylated group, respectively. The hazard ratio for death in the methylated group was 1.64 (95\% CI, 0.48 to $5.60 ; P=0.426$ ) (Fig. 3).

Thirty-eight of the patient samples had elevated DNA concentrations compared to the normal controls (Fig. 1). When analyzing all patients, the 5-year OS rates were 63.2 and $63.6 \%$ in the group with elevated DNA concentrations and the group with normal DNA concentrations, respectively. The hazard ratio for death in the group with elevated DNA concentrations was 0.98 (95\% CI, 0.45 to 2.12; $P=0.963$ ) (Additional file 4: Figure S3).

The 5-year OS rates for patients receiving rituximab were 41.7 and $70.2 \%$ in the DAPK1 methylated and unmethylated group, respectively. The hazard ratio for death in the methylated group was 2.56 (95\% CI, 1.03 to $6.35 ; P=0.036$ ), and the 5 -year OS rates were 50.0 and $67.3 \%$ in the $D B C 1$ methylated and unmethylated group, respectively. The hazard ratio for death in the methylated group was $1.80(95 \% \mathrm{CI}, 1.03$ to $4.92 ; P=0.245)$ (Additional file 5: Figure S4).

\section{DAPK1 methylation status according to patient characteristics}

The clinical characteristics of the DLBCL patients as a function of DAPK1 methylation status are shown in Table 1. No significant differences in patient demographics or disease characteristics according to DAPK1 methylation status were observed, with the exception of stage, as all patients with aberrant DAPK1 methylation had stage III or IV cancer. This was expected as it has been shown in solid tumors that patients with an advanced stage are more likely to have detectable tumor-derived cfDNA in plasma as compared to patients with localized disease [29].

\section{Multivariate analysis of survival according to DAPK1 methylation status}

For most baseline risk factors, including male sex, age above 60 years, extranodal involvement, poor performance 

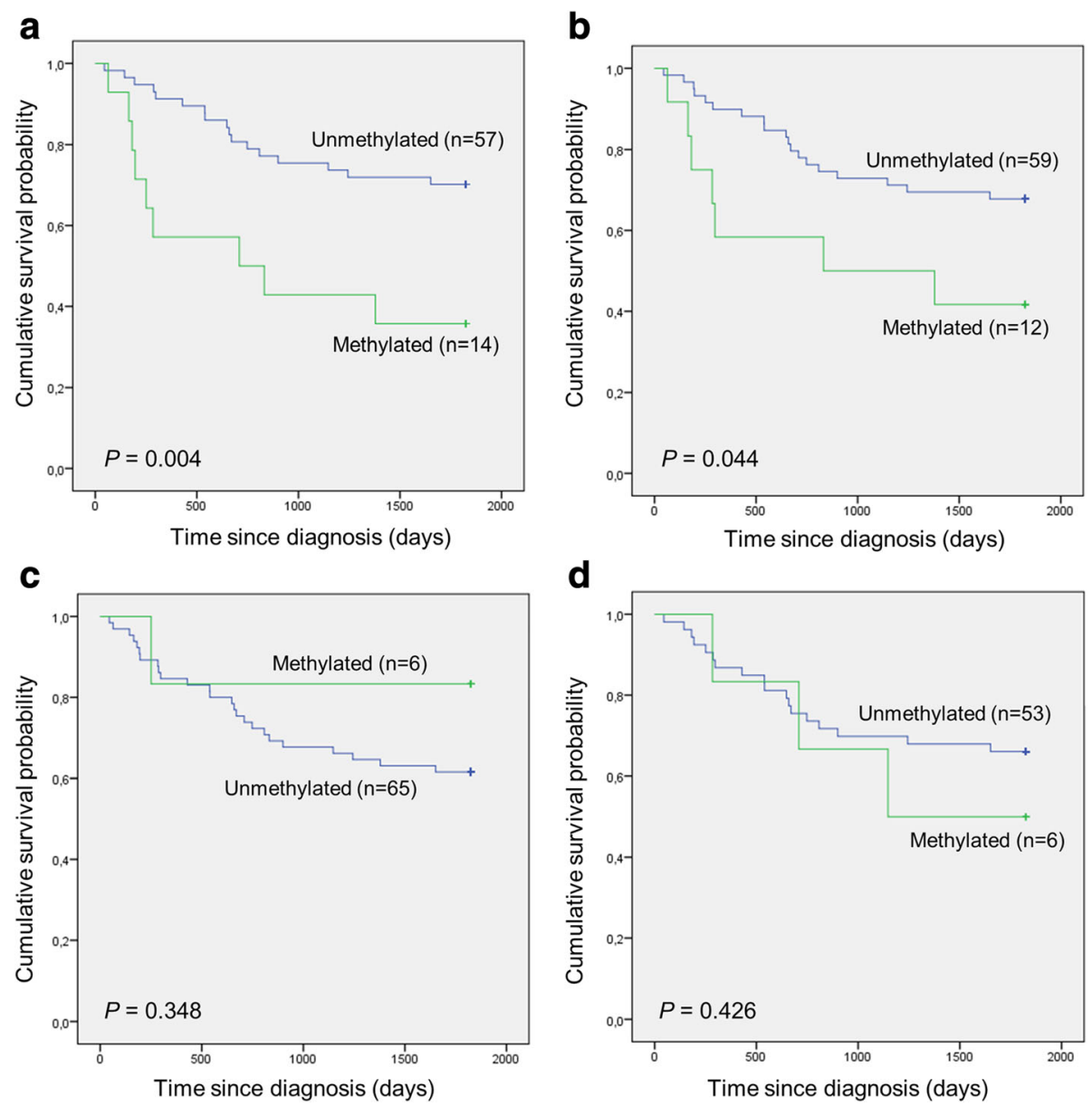

Fig. 3 Overall survival of the entire cohort according to methylation status. a DAPK1. b DBC1. c MIR34A. d MIR34B/C

score, and high IPI, a trend towards a poor OS was observed as expected. However, this was not statistically significant for any of them, possible due to the limited sample size (Table 2). Therefore, the fact that aberrant DAPK1 methylation was a highly significant predictor of overall survival in this cohort of limited size emphasize its high potential as a prognostic marker in DLBCL. To further substantiate our findings, we performed multivariate analyses of survival according to DAPK1 methylation status. All baseline risk factors (gender, age, LDH, extranodal involvement, performance score, stadium, B symptoms, and treatment with rituximab) were included in the Cox proportional hazard model. The model identified methylation of DAPK1 as an independent prognostic factor for OS. The HR for DAPK1 methylation was 8.9 (95\% CI 2.7-29.3, $P<0.0007)$. None of the other baseline risk factors were significant with the exception of male sex and poor performance score (Table 3 ).

\section{Changes in methylation levels during treatment}

Methylation levels for each of the markers were compared between the diagnostic sample and the sample collected 3 months after the end of treatment for each of the individual surviving patients. All patients with aberrant DAPK1 methylation at the time of diagnosis who were alive after the end of treatment showed a decrease in methylation levels, and all except two patients had methylation levels within the normal range after treatment (Fig. 4a). For $D B C 1,11$ of the patients showed a greater than $5 \%$ decrease in methylation levels, while 10 of the patients showed a greater than $5 \%$ increase. Altogether, aberrant methylation was detected in six of the patients after treatment (Fig. 4b). For MIR34A, one patient showed a greater than $5 \%$ decrease in the methylation level, and one patient showed a greater than $5 \%$ increase. Altogether, aberrant methylation was detected in four of the patients after treatment (Fig. 4c). For $M I R 34 B / C$, two patients showed a greater than $5 \%$ decrease in methylation levels, and one patient showed a greater than $5 \%$ increase. Altogether, aberrant methylation was detected in five of the patients after treatment (Fig. 4d).

None of the patients had a decrease in DAPK1 methylation and an increase in $D B C 1$ methylation and vice 
Table 1 Clinical characteristics of the DLBCL patients according to DAPK1 methylation status

\begin{tabular}{|c|c|c|c|c|}
\hline & $\begin{array}{l}\text { Total } \\
(n=71)\end{array}$ & $\begin{array}{l}\text { Unmethylated } \\
(n=57)\end{array}$ & $\begin{array}{l}\text { Methylated } \\
(n=14)\end{array}$ & $P$ value \\
\hline Sex & & & & 0.136 \\
\hline Men & 38 & 33 & 5 & \\
\hline Women & 33 & 24 & 9 & \\
\hline $\begin{array}{l}\text { Extranodal } \\
\text { involvement }\end{array}$ & & & & 0.098 \\
\hline Yes & 53 & 40 & 13 & \\
\hline No & 18 & 17 & 1 & \\
\hline Stage & & & & 0.015 \\
\hline$|-| \mid$ & 18 & 18 & 0 & \\
\hline III-IV & 53 & 39 & 14 & \\
\hline Elevated $\mathrm{LDH}^{\mathrm{b}}$ & & & & 1.000 \\
\hline Yes & 51 & 40 & 11 & \\
\hline No & 17 & 14 & 3 & \\
\hline B symptoms ${ }^{b}$ & & & & 1.000 \\
\hline Yes & 20 & 16 & 4 & \\
\hline No & 49 & 39 & 10 & \\
\hline IPI score ${ }^{b}$ & & & & 0.404 \\
\hline $0-2$ & 26 & 22 & 4 & \\
\hline $3-5$ & 42 & 32 & 10 & \\
\hline $\begin{array}{l}\text { Performance } \\
\text { score }^{\mathrm{a}}\end{array}$ & & & & 1.000 \\
\hline $0-2$ & 62 & 50 & 12 & \\
\hline $3-4$ & 9 & 7 & 2 & \\
\hline Response $^{b}$ & & & & 0.367 \\
\hline CR & 51 & 43 & 8 & \\
\hline $\mathrm{PD} / \mathrm{PR}$ & 10 & 7 & 3 & \\
\hline Mors & 4 & 2 & 2 & \\
\hline $\begin{array}{l}\text { Age at diagnosis } \\
\text { (grouped) }\end{array}$ & & & & 0.959 \\
\hline$<60$ years & 30 & 24 & 6 & \\
\hline$\geq 60$ years & 41 & 33 & 8 & \\
\hline Age at diagnosis & & & & 0.653 \\
\hline $\begin{array}{l}\text { Age, mean } \\
\text { (range) }\end{array}$ & $\begin{array}{l}60 \text { years } \\
(23-85)\end{array}$ & $\begin{array}{l}60 \text { years } \\
(23-85)\end{array}$ & $\begin{array}{l}59 \text { years } \\
(35-72)\end{array}$ & \\
\hline Rituximab $^{b}$ & & & & 1.000 \\
\hline Yes & 59 & 47 & 12 & \\
\hline No & 11 & 9 & 2 & \\
\hline
\end{tabular}

$L D H$ lactate dehydrogenase, $I P I$ international prognostic index, $C R$ complete response, $P D$ progressive disease, $P R$ partial response

aEastern Cooperative Oncology Group

${ }^{\mathrm{b}}$ Data was not available for all patients

versa (Fig. 5), indicating that the aberrant methylation is tumor-specific.

For 14 of the patients with a $D A P K 1$ and/or $D B C 1$ methylated sample at the time of diagnosis, one or two samples collected during treatment were available. These
Table 2 Impact of clinicopathological parameters on OS in DLBCL

\begin{tabular}{|c|c|c|c|}
\hline & Total $(n=71)$ & Number of events & $P$ value \\
\hline Sex & & & 0.219 \\
\hline $\begin{array}{l}\text { Men } \\
\text { Women }\end{array}$ & $\begin{array}{l}38 \\
33\end{array}$ & $\begin{array}{l}16 \\
10\end{array}$ & \\
\hline Extranodal involvement & & & 0.068 \\
\hline $\begin{array}{l}\text { Yes } \\
\text { No }\end{array}$ & $\begin{array}{l}53 \\
18\end{array}$ & $\begin{array}{l}23 \\
3\end{array}$ & \\
\hline Stage & & & 0.520 \\
\hline $\begin{array}{l}\text { I-II } \\
\text { III-IV }\end{array}$ & $\begin{array}{l}18 \\
53\end{array}$ & $\begin{array}{l}8 \\
18\end{array}$ & \\
\hline Elevated LDH ${ }^{\mathrm{b}}$ & & & 0.210 \\
\hline $\begin{array}{l}\text { Yes } \\
\text { No }\end{array}$ & $\begin{array}{l}51 \\
17\end{array}$ & $\begin{array}{l}16 \\
8\end{array}$ & \\
\hline B symptoms ${ }^{b}$ & & & 0.149 \\
\hline $\begin{array}{l}\text { Yes } \\
\text { No }\end{array}$ & $\begin{array}{l}20 \\
49\end{array}$ & $\begin{array}{l}10 \\
15\end{array}$ & \\
\hline IPI score ${ }^{b}$ & & & 0.431 \\
\hline $\begin{array}{l}0-2 \\
3-5\end{array}$ & $\begin{array}{l}26 \\
42\end{array}$ & $\begin{array}{l}8 \\
16\end{array}$ & \\
\hline Performance score ${ }^{a}$ & & & 0.114 \\
\hline $\begin{array}{l}0-2 \\
3-4\end{array}$ & $\begin{array}{l}62 \\
9\end{array}$ & $\begin{array}{l}21 \\
5\end{array}$ & \\
\hline Response $^{b}$ & & & 0.061 \\
\hline $\begin{array}{l}\text { CR } \\
\text { PD/PR }\end{array}$ & $\begin{array}{l}51 \\
10\end{array}$ & $\begin{array}{l}14 \\
5\end{array}$ & \\
\hline Age at diagnosis & & & 0.059 \\
\hline $\begin{array}{l}<60 \text { years } \\
\geq 60 \text { years }\end{array}$ & $\begin{array}{l}30 \\
41\end{array}$ & $\begin{array}{l}7 \\
19\end{array}$ & \\
\hline Rituximab $^{b}$ & & & 0.782 \\
\hline $\begin{array}{l}\text { Yes } \\
\text { No }\end{array}$ & $\begin{array}{l}59 \\
11\end{array}$ & $\begin{array}{l}21 \\
4\end{array}$ & \\
\hline
\end{tabular}

$L D H$ lactate dehydrogenase, $I P I$ international prognostic index, $C R$ complete response, $P D$ progressive disease, $P R$ partial response

${ }^{a}$ Eastern Cooperative Oncology Group

${ }^{\mathrm{b}}$ Data was not available for all patients

additional samples were tested for DAPK1 and $D B C 1$ methylation (Fig. 6). For all of these patients, except patient 13, the DAPK1 methylation levels decreased to a level within the normal range after the treatment was initiated. Patient 13 relapsed and died 181 days after diagnosis. Six patients survived at least 5 years following diagnosis, and all of these retained a DAPK1 methylation level within the normal range for all samples collected during and after treatment. One of the patients (patient 4) died less than a week after the DAPK1 methylation level increased to an aberrant level, and two patients (patients 1 and 11) died 9 and 12 weeks, respectively, after a slight increase in DAPK1 methylation levels was measured. Two of the patients (patients 7 and 12) survived for more than 30 weeks following their last DAPK1 methylation measurements, which were within the normal range. The last 
Table 3 Multivariate Cox regression analyses for baseline risk factors in DLBCL

\begin{tabular}{|c|c|c|c|c|}
\hline \multirow[t]{2}{*}{ Baseline risk factor } & \multirow{2}{*}{$\begin{array}{l}\text { Hazard } \\
\text { ratio }\end{array}$} & \multicolumn{2}{|c|}{$95 \%$ hazard ratio confidence limits } & \multirow{2}{*}{$\begin{array}{l}P \\
\text { value }\end{array}$} \\
\hline & & Lower & Upper & \\
\hline Age above 60 years & 2.85 & 0.97 & 8.41 & 0.058 \\
\hline Male sex & 4.10 & 1.41 & 11.92 & 0.010 \\
\hline Poor performance & 5.36 & 1.56 & 18.41 & 0.008 \\
\hline Stage (III-IV) & 0.44 & 0.13 & 1.42 & 0.169 \\
\hline Extranodal involvement & 1.32 & 0.34 & 5.07 & 0.687 \\
\hline B symptoms & 1.80 & 0.68 & 4.80 & 0.238 \\
\hline Not treated with rituximab & 0.55 & 0.15 & 2.10 & 0.383 \\
\hline Elevated LDH & 0.73 & 0.26 & 2.06 & 0.553 \\
\hline DAPK1 methylation & 8.93 & 2.72 & 29.31 & 0.0007 \\
\hline
\end{tabular}

patient (patient 9) died from the disease 11 weeks after the final DAPK1 methylation measurement, which was within the normal range. For several of the surviving patients $D B C 1$ methylation levels increased more than $D A P K 1$ methylation levels, and one patient (patient 10) increased to an aberrant level, but survived more than 5 years following diagnosis.

Altogether, these analyses demonstrate that DAPK1 methylation in cfDNA from plasma has a potential as a marker to assess treatment response in DLBCL.

\section{Discussion}

The possibility to assess tumor-specific molecular characteristics simply by analyzing peripheral blood, without the need for an invasive tumor biopsy, has been an objective in molecular diagnostics for long. A breakthrough in this area came with the discovery of tumor-specific cfDNA and circulating tumor cells in plasma and serum, which led to the concept known as "liquid biopsy" [30].

Different strategies have been employed for the detection of tumor-specific cfDNA in DLBCL [16, 17, 19, 31]. Frickhofen et al. detected rearrangements of the $\operatorname{IgH}$ locus in plasma and serum as a marker of tumor-specific cfDNA and showed that the presence of tumor-specific DNA may be used for monitoring response to treatment in B cell malignancies [17]. However, patients with a negative test result later relapsed, and the specificity of this approach as a response marker is not clear. He et al.

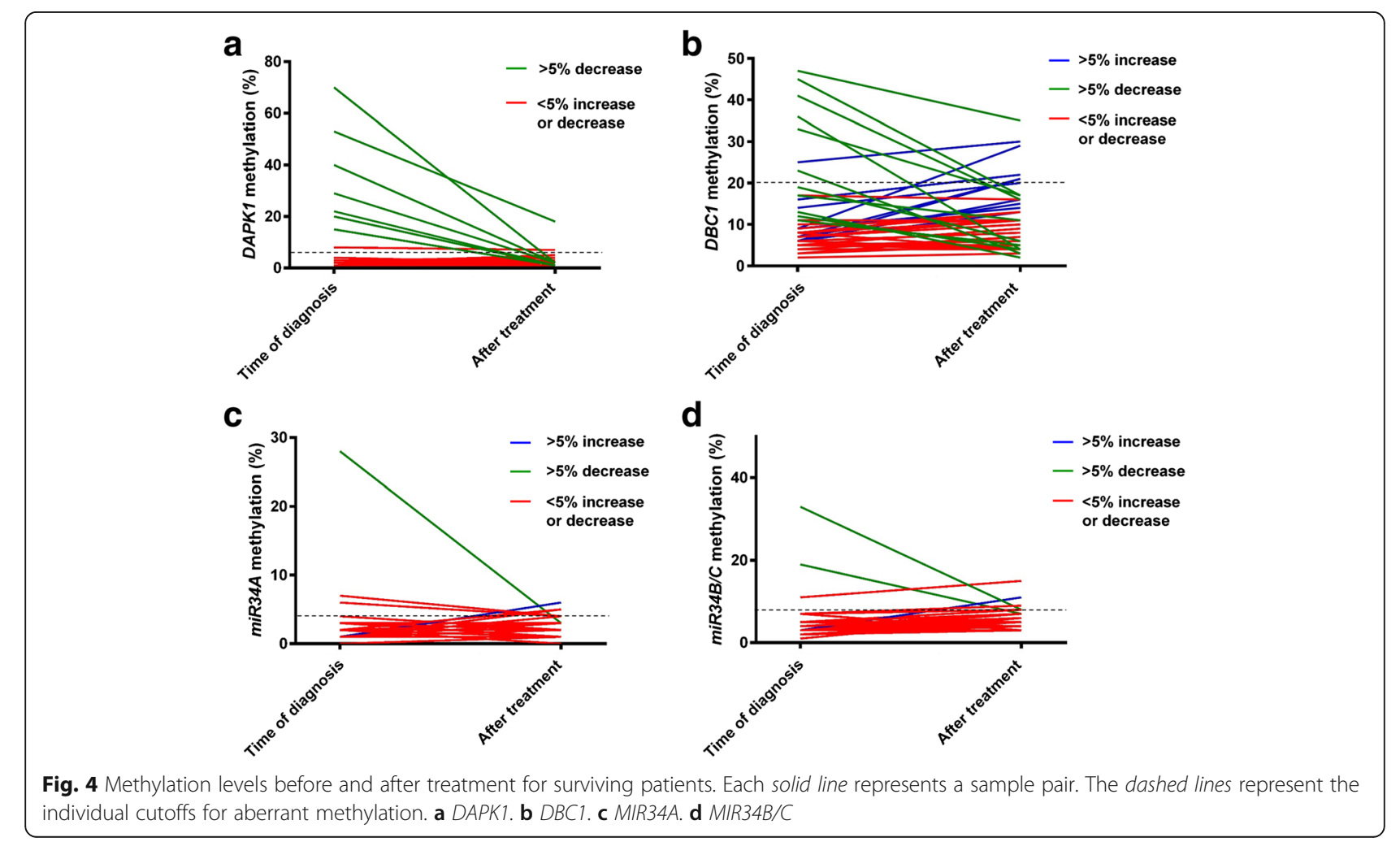




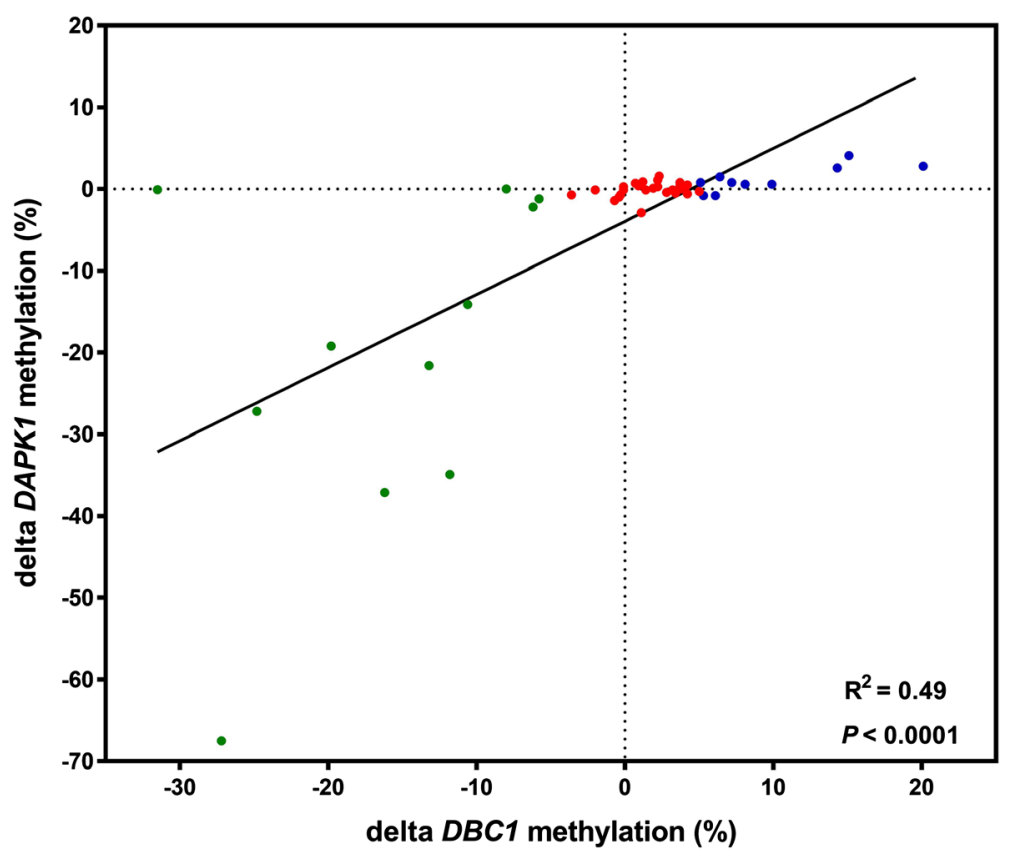

Fig. 5 Correlation between changes in $D A P K 1$ and $D B C 1$ methylation levels during treatment

later refined this approach by using NGS followed by PCR to detect specific rearranged IgH DNA fragments in plasma [16], but the usefulness of this approach as a prognostic marker or as a marker of MRD following therapy was not evaluated. In a preliminary study, Hosny et al. detected TP53 mutations in plasma using direct Sanger sequencing and a PCR-restriction digestion analysis, but no comparisons to clinical outcome were performed [19]. Bohers et al. recently detected tumorspecific cfDNA in plasma by sequencing a panel of 34 genes recurrently mutated in lymphoma using Ion Torrent (Life Technologies) NGS. Their study showed that the mean variant allele frequency can be expected to be lower in cfDNA compared to primary tumor biopsies, and not all mutations present in the tumor samples may be detected in plasma samples [18]. Finally, Jones et al. detected circulating Epstein-Barr virus (EBV) DNA in plasma and serum as a marker of tumor-specific cfDNA, and showed that the presence of tumor-specific DNA correlated with clinical/radiological response. However, this approach is only applicable to EBV-associated lymphoma [31], and it is unclear if the presence of EBV DNA in plasma and/or serum at the time of diagnosis has prognostic value.

We adopted a different approach for the detection of tumor specific cfDNA in DLBCL, namely the detection of aberrant DNA methylation by pyrosequencing. This method is currently in use in clinical settings for the detection of $\mathrm{O}^{6}$-methylguanine-DNA methyltransferase
(MGMT) methylation, which is used as a prognostic and predictive biomarker in glioblastoma treated with alkylating agents [32-34].

As a proof of principle, we selected four tumor suppressor genes, DAPK1, DBC1, MIR34A, and MIR34B/C, which have been shown to be frequently methylated in DLBCL [22-25], and investigated if aberrant methylation levels of these markers could be detected in plasma from patients with DLBCL. Aberrant methylation levels were detected for all markers. However, the frequencies of patients with aberrant methylation were lower than what have previously been observed in DLBCL biopsies [22, 24, 25]. This was expected as cfDNA in plasma contains a larger background of DNA from normal cells in most cases as compared to tumor biopsies. Furthermore, it has also been shown for other malignancies that patients harboring solid tumors with advanced disease are more likely to have detectable tumor-derived cfDNA in plasma as compared to patients with localized disease [29]. In line with this, we observed that the presence of aberrant DAPK1 methylation only occurred for patients with stage III and IV disease.

cfDNA concentrations were elevated at presentation, however, a high DNA concentration did not confer a poor prognosis, and none of the methylation markers we studied were correlated with DNA concentration. This was expected as it has previously been shown that tumor-derived cfDNA, but not non-specific cfDNA, reflects therapeutic response [31], and it has been shown that samples from 


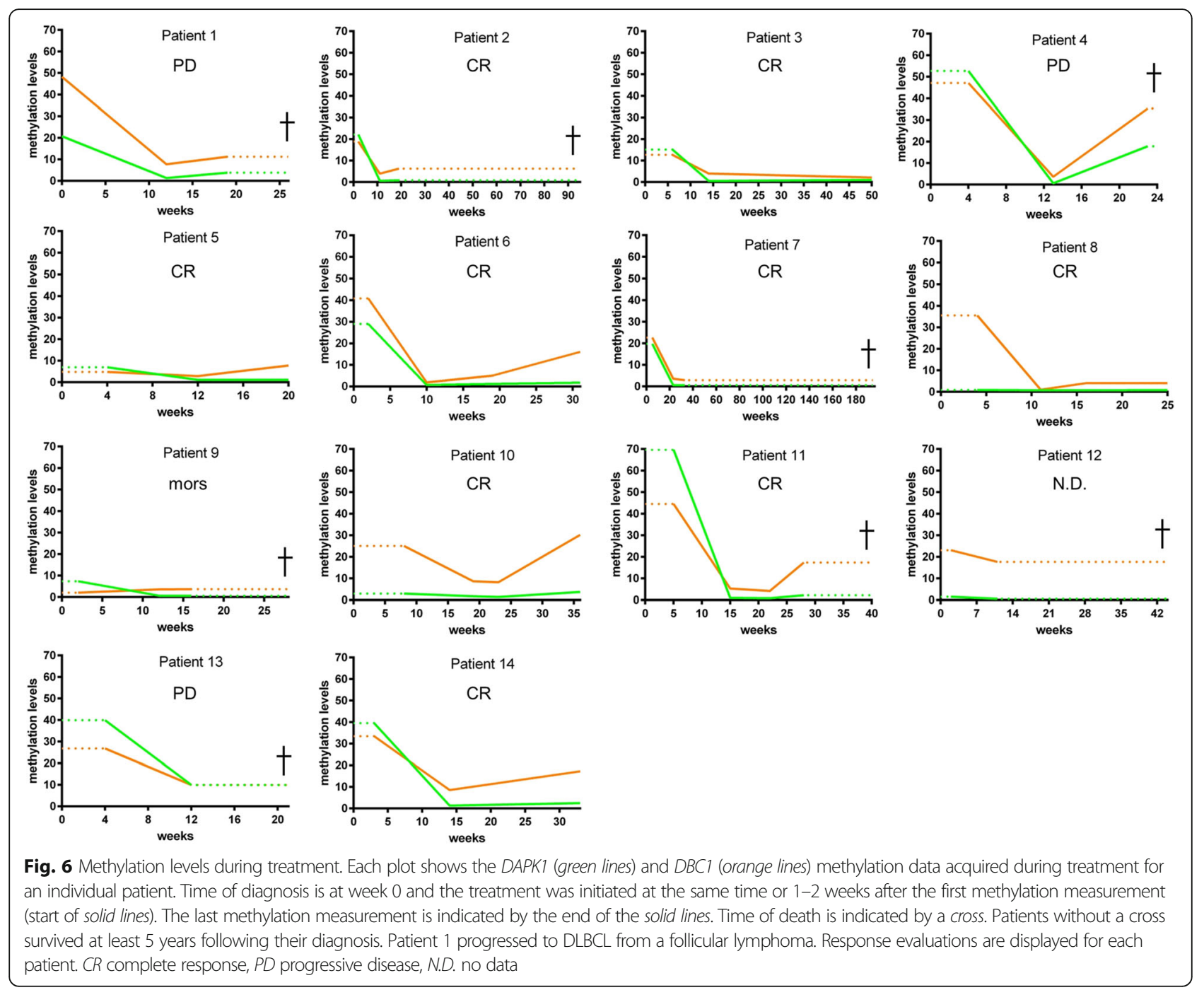

patients with pediatric anaplastic large cell lymphoma with a high percentage of tumor-derived cfDNA tend to have low concentrations of cfDNA [35]. On the other hand, quantification of cfDNA based on qPCR for the $\beta$-globin gene, has been shown to correlate with disease characteristics, such as presence of B symptoms, elevated LDH, and advanced stage disease as well as a poor prognosis [36].

While the detection of tumor-derived cfDNA has potential as a prognostic marker, we hypothesized that the detection of markers in cfDNA, which have prognostic value when detected in primary tumor biopsies, may strengthen that potential. Methylation of DAPK1 in tumor biopsies has proven to be an independent prognostic marker in DLBCL $[22,26]$ and is also methylated in a large proportion of the patients. Indeed, we found methylation of the DAPK1 gene to be a strong predictor of OS and it remained statistically significant when correcting for gender, age, $\mathrm{LDH}$, extranodal involvement, performance score, stage, B symptoms, and treatment with rituximab. Compared to DAPK1 methylation in DLBCL biopsies, a much smaller proportion of the patients have aberrant methylation in cfDNA from plasma, possibly because only the more advanced tumors shed DNA into the circulation. This is very important as it is of exceptional clinical importance to be able to identify a relatively small group of patients who are not responding to current treatment modalities, rather than to identify a small group of patients doing remarkably well, as is the case for patients with an unmethylated DLBCL biopsy [22]. Another important finding was that patients with DAPK1 methylated cfDNA at time of diagnosis, who became long-term survivors, lost the aberrant methylation after treatment initiation. Conversely, patients that maintained or regained aberrant DAPK1 methylation died soon thereafter. Thus, based on these data, we suggest that the small group of patients with aberrant DAPK1 methylation in plasma at the time of diagnosis should be monitored for DAPK1 methylation during treatment and could 
potentially be selected for relapse treatment if the methylation level increases. A number of new agents have shown promising results for the treatment of relapsed/refractory DLBCL used as single-agent or in combination with rituximab-based chemotherapy [37].

At this time, it is unknown if DAPK1 methylation has functional importance for the resistant/relapsing clones. If this is the case, it is tempting to speculate whether DNA methyltransferase inhibitors should be added to the salvage therapy in these patients as azacitidine plus standard chemoimmunotherapy in high-risk patients with newly diagnosed DLBCL is well tolerated and yield a high rate of complete remission [38].

Finally, it may be possible in the future to reconstitute the expression of DAPK1 in patients lacking this important tumor suppressor as delivery of its constitutive kinase domain via a CD22-specific immunoligand has shown remarkable in vitro efficacy and selectivity in preclinical testing [39].

\section{Conclusions}

Aberrant methylation of cfDNA can be detected in plasma from DLBCL patients and methylation of DAPK1 has a strong potential as an independent prognostic marker and may also be used to assess treatment response. However, these results need to be confirmed in additional independent and larger cohorts of DLBCL patients before testing for $D A P K 1$ methylation of cfDNA should be incorporated into routine clinical practice. Nevertheless, this study highlights the potential of liquid biopsies in DLBCL as a prognostic tool and for monitoring patients during and following treatment.

\section{Additional files}

Additional file 1: Table S1. Details of the pyrosequencing assays. (TIF $14 \mathrm{~kb}$ )

Additional file 2: Figure S1. DAPKI methylation levels according to methylation levels of the other markers. (a) DBCI. (b) MIR34A. (c) MIR34B/C. (TIF $990 \mathrm{~kb}$ )

Additional file 3: Figure S2. Methylation levels according to DNA concentrations. (a) DAPKI. (b) DBCl (c) MIR34A. (d) MIR34B/C. (TIF $1 \mathrm{mb}$ )

Additional file 4: Figure S3. Overall survival according to DNA concentrations. (TIF 593 kb)

Additional file 5: Figure S4. Overall survival of the rituximab treated patients according to methylation status. (a) DAPKI. (b) DBCI. (TIF 754 kb)

\section{Acknowledgements}

We would like to acknowledge the patients for giving consent to participate in this study.

\section{Funding}

This work was supported by grants to KG from The Novo Nordisk Foundation, The van Andel Research Institute, and The DanStem collaboration and by grants from The Danish Cancer Society to KG and LSK. The funders had no role in study design, data collection and analysis, decision to publish, or preparation of the manuscript.

\section{Availability of data and materials}

The raw pyrosequencing data generated and analyzed during the current study are available from the corresponding author on reasonable request.

\section{Authors' contributions}

LSK, JWH, and SSK carried out the molecular genetic studies. LSK, JWH, SSK and LBSH analyzed the data. PDNB collected the clinical data. OBP, DT, and PDNB collected the human material studied. LSK, JWH, and KG conceived the study. LSK wrote the manuscript. LSK and KG contributed reagents and materials. All authors revised the manuscript for important intellectual content and read and approved the final manuscript.

\section{Competing interests}

The authors declare that they have no competing interests.

Consent for publication

Not applicable.

\section{Ethics approval and consent to participate}

The study was performed according to the Declaration of Helsinki and Danish legislation. Permissions were given from the Danish Data Protection Agency (30-1225) and the ethical committee for the Capital Region of Denmark (H-15007182 and M-20090237).

\section{Author details}

'Department of Haematology, Rigshospitalet, Blegdamsvej 9, Copenhagen, Denmark. ${ }^{2}$ Department of Clinical Immunology, Næstved Sygehus,

Ringstedgade 77A, Næstved, Denmark.

Received: 12 April 2016 Accepted: 29 August 2016

Published online: 07 September 2016

\section{References}

1. Morton LM, Wang SS, Devesa SS, Hartge P, Weisenburger DD, Linet MS. Lymphoma incidence patterns by WHO subtype in the United States, 19922001. Blood. 2006;107(1):265-76.

2. Coiffier B, Lepage E, Briere J, Herbrecht R, Tilly H, Bouabdallah R, Morel P, Van Den Neste E, Salles G, Gaulard P, et al. CHOP chemotherapy plus rituximab compared with $\mathrm{CHOP}$ alone in elderly patients with diffuse large B-cell lymphoma. N Engl J Med. 2002;346(4):235-42.

3. Larouche JF, Berger F, Chassagne-Clement C, Ffrench M, Callet-Bauchu E, Sebban C, Ghesquieres H, Broussais-Guillaumot F, Salles G, Coiffier B. Lymphoma recurrence 5 years or later following diffuse large B-cell lymphoma: clinical characteristics and outcome. J Clin Oncol. 2010;28(12):2094-100.

4. El-Galaly TC, Jakobsen LH, Hutchings M, de Nully BP, Nilsson-Ehle H, Szekely E, Mylam KJ, Hjalmar V, Johnsen HE, Bogsted M, et al. Routine imaging for diffuse large B-cell lymphoma in first complete emission does not improve post-treatment survival: a Danish-Swedish population-based study. J Clin Oncol. 2015;33(34):3993-8.

5. Dawson SJ, Seymour JF. Large B-cell lymphoma: is the future written in the blood? Lancet Oncol. 2015;16(5):481-3.

6. Jones PA. Functions of DNA methylation: islands, start sites, gene bodies and beyond. Nat Rev Genet. 2012;13(7):484-92.

7. Hopp L, Loffler-Wirth H, Binder H. Epigenetic heterogeneity of B-cell lymphoma: DNA methylation, gene expression and chromatin states. Genes (Basel). 2015;6(3):812-40

8. Asmar F, Punj V, Christensen J, Pedersen MT, Pedersen A, Nielsen AB, Hother C, Ralfkiaer U, Brown P, Ralfkiaer E, et al. Genome-wide profiling identifies a DNA methylation signature that associates with TET2 mutations in diffuse large B-cell lymphoma. Haematologica. 2013;98(12):1912-20.

9. Morin RD, Johnson NA, Severson TM, Mungall AJ, An J, Goya R, Paul JE, Boyle M, Woolcock BW, Kuchenbauer F, et al. Somatic mutations altering EZH2 (Tyr641) in follicular and diffuse large B-cell lymphomas of germinalcenter origin. Nat Genet. 2010;42(2):181-5.

10. Morin RD, Mendez-Lago M, Mungall AJ, Goya R, Mungall KL, Corbett RD, Johnson NA, Severson TM, Chiu R, Field M, et al. Frequent mutation of histone-modifying genes in non-Hodgkin lymphoma. Nature. 2011; 476(7360):298-303.

11. Pan H, Jiang Y, Boi M, Tabbo F, Redmond D, Nie K, Ladetto M, Chiappella A, Cerchietti $\mathrm{L}$, Shaknovich $\mathrm{R}$, et al. Epigenomic evolution in diffuse large B-cell lymphomas. Nat Commun. 2015;6:6921. 
12. Mikeska T, Craig JM. DNA methylation biomarkers: cancer and beyond Genes (Basel). 2014;5(3):821-64.

13. How Kit A, Nielsen HM, Tost J. DNA methylation based biomarkers: practical considerations and applications. Biochimie. 2012;94(11):2314-37.

14. Schwarzenbach $H$, Hoon DS, Pantel K. Cell-free nucleic acids as biomarkers in cancer patients. Nat Rev Cancer. 2011;11(6):426-37.

15. Roschewski M, Dunleavy K, Pittaluga S, Moorhead M, Pepin F, Kong K, Shovlin M, Jaffe ES, Staudt LM, Lai C, et al. Circulating tumour DNA and CT monitoring in patients with untreated diffuse large B-cell lymphoma: a correlative biomarker study. Lancet Oncol. 2015;16(5):541-9.

16. He J, Wu J, Jiao Y, Wagner-Johnston N, Ambinder RF, Diaz Jr LA, Kinzler KW, Vogelstein B, Papadopoulos N. IgH gene rearrangements as plasma biomarkers in non-Hodgkin's lymphoma patients. Oncotarget. 2011;2(3):178-85.

17. Frickhofen N, Muller E, Sandherr M, Binder T, Bangerter M, Wiest C, Enz M, Heimpel $\mathrm{H}$. Rearranged Ig heavy chain DNA is detectable in cell-free blood samples of patients with B-cell neoplasia. Blood. 1997;90(12):4953-60.

18. Bohers E, Viailly PJ, Dubois S, Bertrand P, Maingonnat C, Mareschal S, Ruminy P, Picquenot JM, Bastard C, Desmots F, et al. Somatic mutations of cell-free circulating DNA detected by next-generation sequencing reflect the genetic changes in both germinal center B-cell-like and activated B-celllike diffuse large B-cell lymphomas at the time of diagnosis. Haematologica. 2015;100(7):e280-4.

19. Hosny G, Farahat N, Hainaut P. TP53 mutations in circulating free DNA from Egyptian patients with non-Hodgkin's lymphoma. Cancer Lett. 2009;275(2): 234-9.

20. Warton K, Lin V, Navin T, Armstrong NJ, Kaplan W, Ying K, Gloss B, Mangs H, Nair SS, Hacker NF, et al. Methylation-capture and next-generation sequencing of free circulating DNA from human plasma. BMC Genomics. 2014;15:476

21. El Messaoudi S, Rolet F, Mouliere F, Thierry AR. Circulating cell free DNA: preanalytical considerations. Clin Chim Acta. 2013;424:222-30.

22. Kristensen LS, Asmar F, Dimopoulos K, Nygaard MK, Aslan D, Hansen JW Ralfkiaer E, Gronbaek K. Hypermethylation of DAPK1 is an independent prognostic factor predicting survival in diffuse large B-cell lymphoma. Oncotarget. 2014;5(20):9798-810.

23. Kristensen LS, Treppendahl MB, Asmar F, Girkov MS, Nielsen HM, Kjeldsen TE, Ralfkiaer E, Hansen LL, Gronbaek K. Investigation of MGMT and DAPK1 methylation patterns in diffuse large B-cell lymphoma using allelic MSPpyrosequencing. Sci Rep. 2013;3:2789.

24. Gronbaek K, Ralfkiaer U, Dahl C, Hother C, Burns JS, Kassem M, Worm J, Ralfkiaer EM, Knudsen LM, Hokland P, et al. Frequent hypermethylation of DBC1 in malignant lymphoproliferative neoplasms. Mod Pathol. 2008;21(5):632-8.

25. Asmar F, Hother C, Kulosman G, Treppendahl MB, Nielsen HM, Ralfkiaer U, Pedersen A, Moller MB, Ralfkiaer E, de Nully BP, et al. Diffuse large B-cell lymphoma with combined TP53 mutation and MIR34A methylation: Another "double hit" lymphoma with very poor outcome? Oncotarget. 2014;5(7):1912-25.

26. Amara K, Trimeche M, Ziadi S, Laatiri A, Hachana M, Korbi S. Prognostic significance of aberrant promoter hypermethylation of CPG islands in patients with diffuse large B-cell lymphomas. Ann Oncol. 2008:19(10):1774-86.

27. Pedersen OB, Erikstrup C, Kotze SR, Sorensen E, Petersen MS, Grau K, Ullum $H$. The Danish Blood Donor Study: a large, prospective cohort and biobank for medical research. Vox Sang. 2012;102(3):271.

28. Kristensen LS, Hansen LL. PCR-based methods for detecting single-locus DNA methylation biomarkers in cancer diagnostics, prognostics, and response to treatment. Clin Chem. 2009:55(8):1471-83.

29. Bettegowda C, Sausen M, Leary RJ, Kinde I, Wang Y, Agrawal N, Bartlett BR, Wang $\mathrm{H}$, Luber $\mathrm{B}$, Alani RM, et al. Detection of circulating tumor DNA in earlyand late-stage human malignancies. Sci Transl Med. 2014;6(224):224ra224.

30. Diaz Jr LA, Bardelli A. Liquid biopsies: genotyping circulating tumor DNA. Clin Oncol. 2014;32(6):579-86.

31. Jones K, Nourse JP, Keane C, Crooks P, Gottlieb D, Ritchie DS, Gill D, Gandhi MK. Tumor-specific but not nonspecific cell-free circulating DNA can be used to monitor disease response in lymphoma. Am J Hematol. 2012;87(3): 258-65.

32. Kristensen LS, Michaelsen SR, Dyrbye H, Aslan D, Grunnet K, Christensen IJ, Poulsen HS, Gronbaek K, Broholm H. Assessment of quantitative and allelic MGMT methylation patterns as a prognostic marker in glioblastoma. J Neuropathol Exp Neurol. 2016:75(3):246-55.

33. Esteller M, Garcia-Foncillas J, Andion E, Goodman SN, Hidalgo OF, Vanaclocha V, Baylin SB, Herman JG. Inactivation of the DNA-repair gene
MGMT and the clinical response of gliomas to alkylating agents. N Engl J Med. 2000:343(19):1350-4.

34. Hegi ME, Diserens AC, Gorlia T, Hamou MF, de Tribolet N, Weller M, Kros JM, Hainfellner JA, Mason W, Mariani L, et al. MGMT gene silencing and benefit from temozolomide in glioblastoma. N Engl J Med. 2005;352(10):997-1003.

35. Mussolin L, Burnelli R, Pillon M, Carraro E, Farruggia P, Todesco A, Mascarin M, Rosolen A. Plasma cell-free DNA in paediatric lymphomas. J Cancer. 2013:4(4):323-9.

36. Hohaus S, Giachelia M, Massini G, Mansueto G, Vannata B, Bozzoli V, Criscuolo M, D'Alo F, Martini M, Larocca LM, et al. Cell-free circulating DNA in Hodgkin's and non-Hodgkin's lymphomas. Ann Oncol. 2009;20(8):1408-13.

37. Camicia R, Winkler HC, Hassa PO. Novel drug targets for personalized precision medicine in relapsed/refractory diffuse large B-cell lymphoma: a comprehensive review. Mol Cancer. 2015;14(1):207.

38. Clozel T, Yang S, Elstrom RL, Tam W, Martin P, Kormaksson M, Banerjee S, Vasanthakumar A, Culjkovic B, Scott DW, et al. Mechanism-based epigenetic chemosensitization therapy of diffuse large B-cell lymphoma. Cancer Discov. 2013;3(9):1002-19.

39. Lilienthal N, Lohmann G, Crispatzu G, Vasyutina E, Zittrich S, Mayer P, Herling CD, Tur MK, Hallek M, Pfitzer G, et al. A novel recombinant antiCD22 immunokinase delivers proapoptotic activity of death-associated protein kinase (DAPK) and mediates cytotoxicity in neoplastic B cells. Mol Cancer Ther. 2016;15(5):971-84

\section{Submit your next manuscript to BioMed Central and we will help you at every step:}

- We accept pre-submission inquiries

- Our selector tool helps you to find the most relevant journal

- We provide round the clock customer support

- Convenient online submission

- Thorough peer review

- Inclusion in PubMed and all major indexing services

- Maximum visibility for your research

Submit your manuscript at www.biomedcentral.com/submit
) Biomed Central 